Original Research Article

\title{
Effectiveness of a module to promote competency in adverse drug reaction reporting in undergraduate medical students
}

\author{
Nazuk Sharma*, Taruna Sharma, Suman Bala
}

Department of Pharmacology, Himalayan Institute of Medical Science, SRHU, Dehradun, Uttarakhand, India

Received: 22 January 2018 Accepted: 05 March 2018

*Correspondence to:

Dr. Nazuk Sharma, Email:nazuk89@yahoo.com

Copyright: (C) the author(s), publisher and licensee Medip Academy. This is an openaccess article distributed under the terms of the Creative Commons Attribution NonCommercial License, which permits unrestricted noncommercial use, distribution, and reproduction in any medium, provided the original work is properly cited.

\begin{abstract}
Background: Adverse drug reaction (ADR) under-reporting is a hindrance to the implementation of Pharmacovigilance Program of India. This is essentially due to lack of ADR reporting culture among healthcare professionals. Thus, study was conducted to assess and enhance awareness about ADRs and strengthen reporting among medical undergraduates.

Methods: This is an interventional crossover study. A total of 140 students of 2nd professional, MBBS were included and divided into two groups of 70 each. In phase 1, group A was given a didactic lecture (DL) on ADR and pharmacovigilance. Group B was also given DL with an addition of a case narrative exercise and they were asked to fill an ADR form. Both groups were assessed based on an MCQ questionnaire for knowledge and skill. After 15 days of washout period, groups were crossed and reassessed. Feedback from students was taken on a 5 point Likert's scale.

Results: The mean scores of batch A without case was $17.5 \pm 3$ out of a total score of 25 marks, which showed improvement with case narrative and mean increased to $19.6 \pm 2.4$ (p 0.05). Similarly, Batch B showed improvement as well and the mean 17.7 \pm 3.1 score without case narrative increased to 19.2 \pm 2.7 ( $p<0.05$ ). Student's perception of the effectiveness of module-based teaching was positive. Conclusions: Case narrative in addition to didactic lecture enhanced awareness and may strengthen ADR reporting culture among the medical students.
\end{abstract}

Keywords: Adverse drug reaction, Pharmacovigilance, Teaching module

\section{INTRODUCTION}

Drug therapy is an integral part of the medical management. Two major concerns about a drug are its safety and efficacy. Efficacy of a drug can be quantified by its clinical outcomes but same does not hold true for its safety. This is because there are adverse effects of a drug of varying severity which may be uncommon, and many patients may be affected by these adverse effects even before the relationship with the drug is established. There are three possible actions of drug: The one you want, the one you don't want, and the one you don't know about. ${ }^{1}$
Drug therapy has many benefits, but side effects and adverse drug reactions (ADR) are some of its major disadvantages. World health organization (WHO) defines ADR as "a response to a drug that is noxious and unintended, which occurs at doses normally used in man for prophylaxis diagnosis or therapy of disease or for the modification of physiological function". 2 The epidemiological importance of ADR is justified by its high prevalence rate, they account for 3 to $6 \%$ of all hospital admissions and occur in 10 to $15 \%$ of hospitalized patients, thus results in morbidity, prolonged hospitalization, and risk of mortality. ${ }^{3}$ 
World Health Organisation (WHO) initiated its Program for International Drug Monitoring after witnessing the thalidomide drug's dangerous side-effects on unborn babies in 1961. Together with the WHO Collaborating Centre for International Drug Monitoring, Uppsala, WHO promotes PV at the country level. Pharmacovigilance (PV) is defined as "the science and activities relating to the detection, assessment, understanding, and prevention of adverse effects or any other drug-related problem". The primary aim of this program is to enhance patient care and patient safety in regard to the employment of medicines, and to support public health programs by providing reliable, balanced information for the effective assessment of the risk-benefit profile of medicines. ${ }^{4}$

India may be a country with an oversized patient pool and aid professionals, nevertheless, ADR reporting is in its infancy. ${ }^{5}$ India ranks below $1 \%$ in terms of ADR reporting against the world rate of $5 \% .^{6}$ To overcome this problem, the Ministry of Health and Family Welfare, Government of India, has initiated the Pharmacovigilance Program of India (PvPI), operational since July 2010 under the aegis of Central Drug Standard Control Organization. The PV centers collect, communicate and disseminate ADR data by linking with hospitals as well as practitioners. ${ }^{7}$

ADR reporting does not currently seem to be considered part of routine professional practice and is often primarily attributable to the absence of reporting culture among health care professionals. ${ }^{8}$ Reporting of ADR to the concerned authority is a skill which must be developed and reinforced in MBBS students to be a competent and responsible health-care professional. Reporting of ADR to the involved authority may be an ability that should be developed and bolstered in MBBS students to be a competent and accountable health-care skilled.

Medical students who will be the backbone of healthcare delivery in future could play a major role and bring a paradigm shift in successful implementation of this program if adequate knowledge and skill are imparted to them during undergraduate training career, but at present they don't have any significant role which is due to inadequate training to them regarding ADR reporting. The study aims to assess and enhance awareness about ADRs and their reporting and strengthening pharmacovigilance among medical undergraduates of Himalayan Institute of medical sciences, Dehradun.

\section{METHODS}

The study conducted was a prospective, interventional, crossover study, which was initiated after taking approval from the Institutional ethics committee. Students were briefed about the purpose of the study and verbal informed consent was taken. A total of 140 Second professional, MBBS students were included out of a batch of 146 and the students who could not attend either of the session were excluded. The study was conducted in two phases. In both the phases, a total of 140 students were included and divided into two batches A and B of 70 each (Fig.1). For the purpose of the study, a module was formed which included detailed didactic lecture, ADR case narrative, ADR based questionnaire and a feedback form.

\section{Development of lecture on adverse drug reaction}

A detailed lecture was prepared for the better understanding of the adverse drug reactions and pharmacovigilance program of India. It included types of adverse drug reactions, predisposing factors, prevention of adverse drug reactions, details about the history of PvPI and covering important aspects of the subject.

\section{Development of adverse drug reaction case narrative}

The investigator of the project prepared adverse event (AE) case narrative for two different batches. Case narrative included patient details, case history along with dates of the event occurring and date of recovery, description of the events of reaction, relevant investigation done, specific and concomitant treatment given to the patient, treatment given to control the reaction. These narratives were prepared under the guidance of senior faculties. AE case scenarios were thoroughly reviewed, and the changes suggested were incorporated.

\section{Development of ADR based questionnaire}

To assess the skill and knowledge of the participating candidates regarding given ADR reporting training module, a questionnaire including 25 questions was prepared after detailed literature review. The items in both the questionnaires were same. The questionnaire covered were student satisfaction, module implementation, and acquisition of the skill to report ADR. Content validity of these questionnaires was checked by experts in medical education.

\section{Conduction of study}

The study was conducted in two phases with a wash out period of 15 days between both the phases (Figure 1).

\section{Phase I}

In phase I, students in batch A received a detailed didactic lecture covering all the information about the ADR and the Pharmacovigilance Program of India. While students in batch $\mathrm{B}$, in addition to the didactic lecture were exposed to a case narrative. Thus Post lecture they were requested to fill up the standard ADR form (obtained from the website of Indian Pharmacopoeia Commission). ${ }^{9}$ Both batch A and $\mathrm{B}$ students were given a questionnaire based module to be answered in the time allotted.

\section{Phase II}

Phase II was conducted after a washout period of fifteen days. And in this phase batches were crossed. Now, batch 
$B$ received only didactic lecture post which they had to answer the questionnaire. And batch $\mathrm{A}$ in addition to didactic lecture received a case narrative, post which they were requested to fill standard ADR form and answer the questionnaire. Student feedback at the end of study was taken and scored on Likert scale (5-strongly agree, 4agree, 3-neutral, 2-disagree, and 1-strongly disagree).

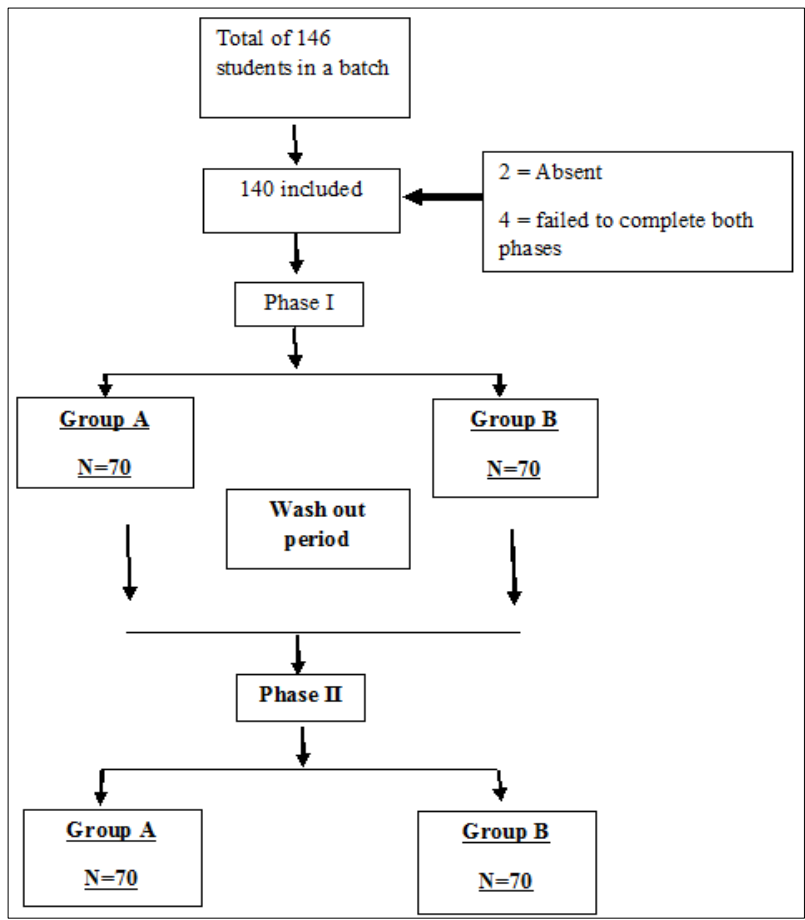

Figure 1: Number of students included in study, along with study protocol $(\mathrm{N}=140)$.

\section{Assessment}

To assess the skill and knowledge of the participating candidates at the end of project questionnaire-based module was scored out of a total of 25 marks (one mark for each correct answer). Standard ADR reporting form filled by participants was evaluated for accuracy and the deficiencies found were discussed in consecutive class. Although, ADR form was not scored

\section{Statistical analysis}

Collected data were analysed using available statistical software Microsoft Excel 2007 and SPSS version 23. Paired t-test was used to compare the data within the group and to compare the performance intergroup unpaired t-test was used. $\mathrm{P}<0.05$ was considered statistically significant. Participant's feedback regarding their views about the exercise was taken by using 5 point Likert's scale.

\section{RESULTS}

The ADR reporting training module was implemented in MBBS students. The mean scores of both the batches showed improvement (Figure 2 and Figure 3).

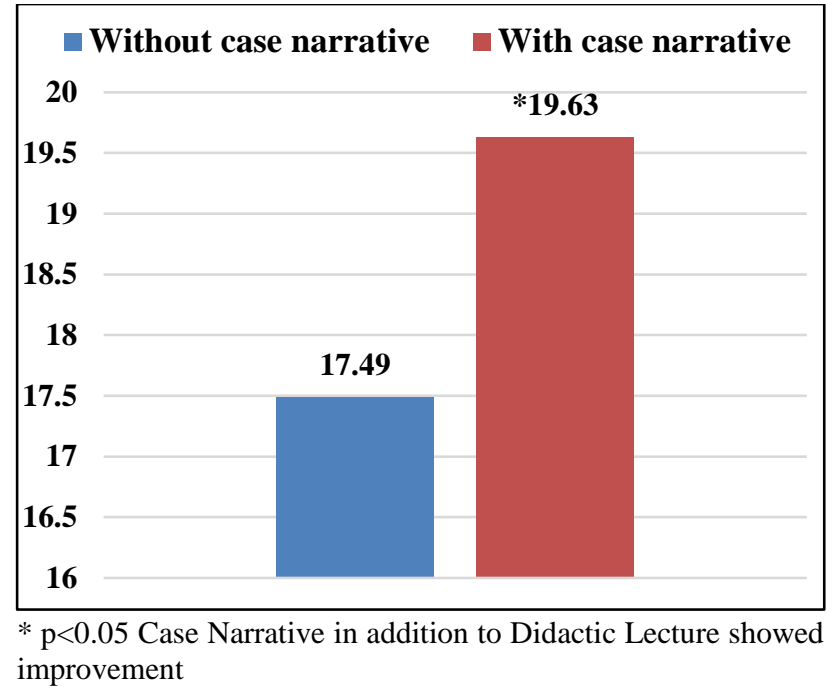

Figure 2: Mean test scores of Batch A out of 25.

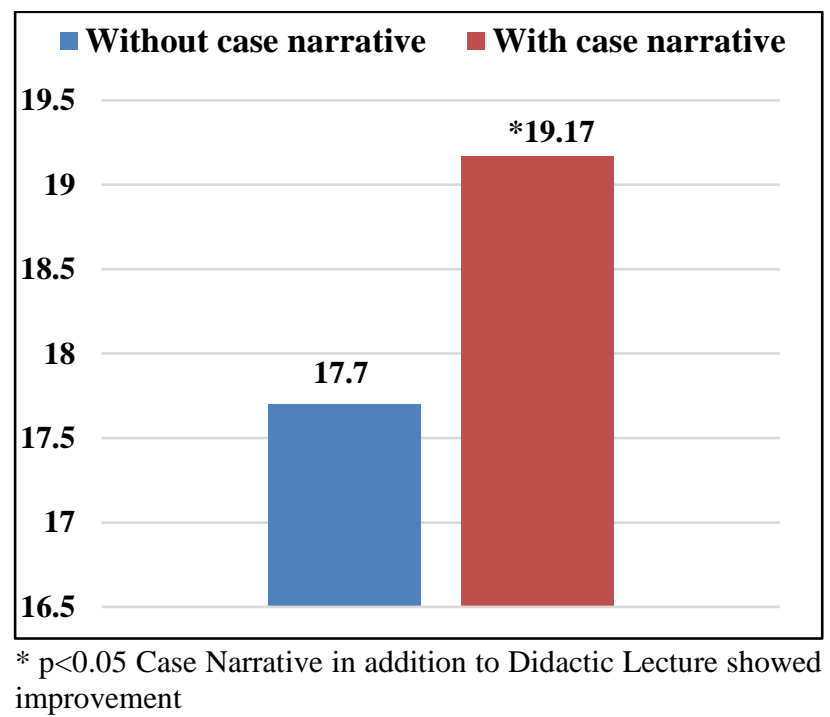

Figure 3: Mean test scores of Batch B out of 25.

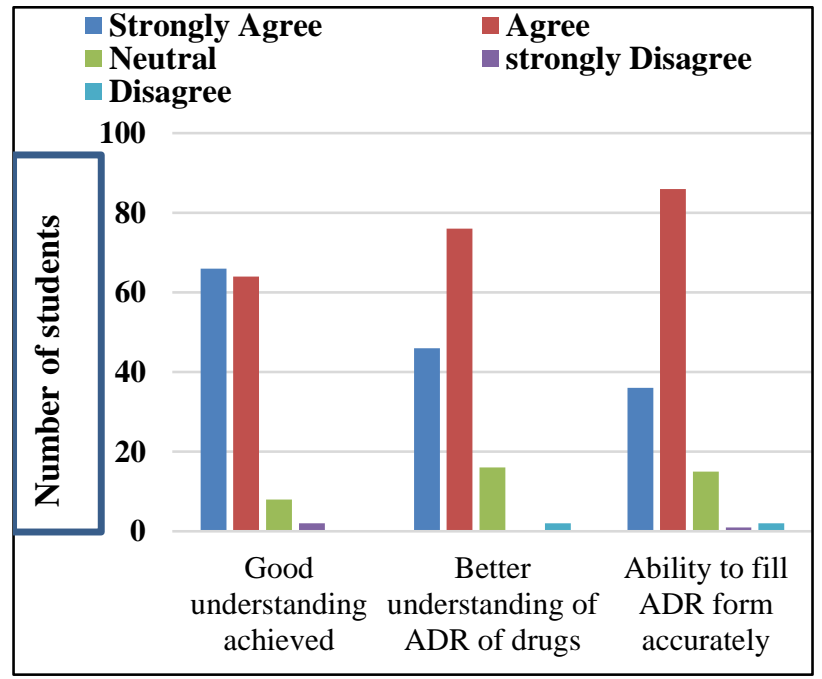

Figure 4: Student feedback regarding understanding of the subject and ability to fill ADR form. 


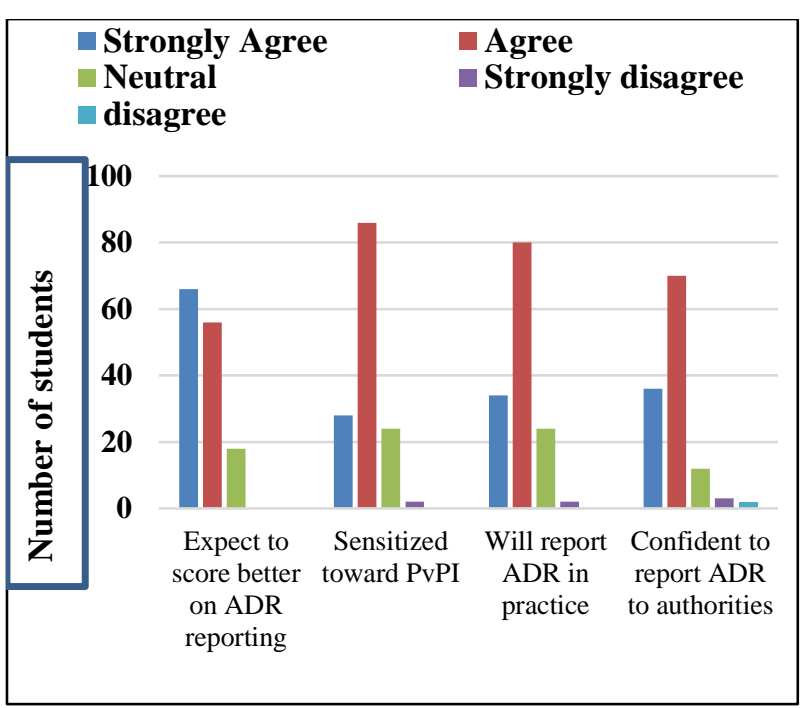

Figure 5: Student feedback regarding sensitization and confidence achieved towards Pharmacovigilance.

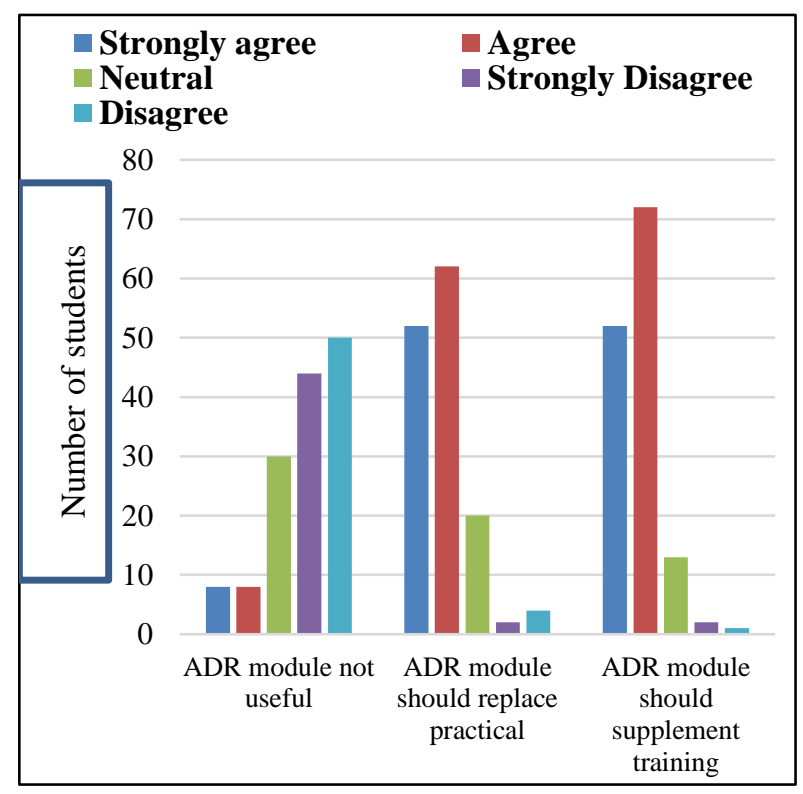

Figure 6: Student Feedback regarding ADR module.

Intergroup mean test scores of both the sessions was indicating that both the groups performed equally well ( $\mathrm{P}$ $>0.05$ ). Student feedback at the end of study was taken (Figure 4, 5 and 6). Figures 4, 5 and 6 shows Student feedback regarding their perception for the module.

\section{DISCUSSION}

Knowledge of the adverse impacts of medications is critical for viable treatment. Informing the potential harm of drug-use to patients is a matter of high priority and should be carried out by every prescriber. Pharmacovigilance assumes an imperative part in the rational utilization of drugs by giving data about ADRs in all inclusive communities. ${ }^{10}$ It has constantly centered around strengthening the reporting of ADR. This study was focused to improve mindfulness and advance the learning of PvPI with the help of a module among the sprouting specialists to grant expertise of detailing ADR in their training.

In this study student's moved from beginner stage to an advanced stage in ADR reporting skill which could be witnessed with the improvement in the mean test scores on addition of a case narrative to the didactic lecture. The mean scores of batch A without case narrative was $17.49 \pm 3$ out of a total score of 25 marks, which showed improvement with case narrative and mean increased to $19.63 \pm 2.4$ ( $p<0.05$ ) (Figure 2). Similarly, Batch B showed improvement as well and the mean $17.70 \pm 3.1$ score without case narrative increased to $19.17 \pm 2.7(\mathrm{p}<0.05)$ (Figure 3). But it is clearly evident that students are sensitized towards the PvPI. A study conducted by Raakhi Kaliprasad Tripathi et al published in 2016 concludes that Module improved the accuracy of filling standard ADR reporting form by students. ${ }^{11}$

More than $90 \%$ of student agreed that they acquired good understanding of the subject. Whereas more than $80 \%$ student felt that they were sensitized towards the PV program and will be able to fill ADR form in practice (Table 1). In this study both the batches performed equally well. Student strongly supported that ADR module should supplement training and their perception of the effectiveness of module based learning was positive. In another study conducted on Malaysian Pharmacy Undergraduates, a survey was done in 14 medical and pharmacy schools based on a questionnaire and it concluded that Pharmacovigilance should be made a core course to ensure effective practice in the area of drug safety and there is an urgent and necessary need for students to be adequately educated and exposed to the contemporary issues and challenges of pharmacovigilance implementation. ${ }^{12}$

The knowledge of students about the safety of a medicine is being strengthened by teaching but reporting culture lags behind. Several studies that explored student's attitudes and perceptions regarding their role in pharmacovigilance have indicated that they were highly appreciated and had positive attitudes regarding pharmacovigilance activities, but needed additional training and education programs to extend their role in the field. ${ }^{13}$ Due to the module, most of the students were sharpened toward the PvPI and now, committed they will report ADR in future.

This is like the impression of Nigerian therapeutic students from Bayero University Kano, Nigeria, on ADR reporting, wherein $82 \%$ students believed that ADR reporting is an obligation of health-care workers and expressed that ADR should be instructed in detail. ${ }^{13}$ In a study done by Sivadasan and Sellappan, final year Malaysian nursing students (67\%) students also gave an opinion that the ADR monitoring program of their country is extremely important and it is their duty to report ADR. ${ }^{14}$ 
Table 1: Feedback questions, scored on 5 point Lickert's scale.

\begin{tabular}{|c|c|c|c|c|c|}
\hline & Strongly Agree & Agree & Neutral & $\begin{array}{l}\text { Strongly } \\
\text { disagree }\end{array}$ & Disagree \\
\hline & \multicolumn{5}{|c|}{ Number of students (Percentage) } \\
\hline Good understanding achieved about PvPI & $66(47.2)$ & $64(46)$ & $8(5.71)$ & $2(1.42)$ & 0 \\
\hline Better understanding of ADR of drugs & $46(33)$ & $76(54.3)$ & $16(11.4)$ & 0 & $2(1.42)$ \\
\hline Ability to fill ADR form accurately & $36(26)$ & $86(61.4)$ & $15(10.71)$ & $1(0.71)$ & $2(1.42)$ \\
\hline Expect to score better on ADR reporting & $66(47.2)$ & $56(40)$ & $18(12.85)$ & 0 & 0 \\
\hline Sensitized toward PvPI & $28(20)$ & 86 (61.4) & $24(17.14)$ & $2(1.42)$ & 0 \\
\hline Will report ADR in practice & $34(24.2)$ & $80(57.1)$ & $24(17.14)$ & $2(1.42)$ & 0 \\
\hline Confident to report ADR to authorities & $36(25.71)$ & $70(50)$ & $29(20.71)$ & $3(2.14)$ & $2(1.42)$ \\
\hline ADR module not useful & $8(5.71)$ & $8(5.71)$ & $30(21.42)$ & $44(31.42)$ & $50(35.7)$ \\
\hline ADR module should replace practical & $52(37.14)$ & $62(44.28)$ & $20(14.28)$ & $2(1.42)$ & $4(2.85)$ \\
\hline ADR module should supplement training & $52(37.14)$ & $72(51.42)$ & $13(9.28)$ & $2(1.42)$ & $1(0.71)$ \\
\hline
\end{tabular}

One of the limitations of the study was a small duration of wash out period. Another was that different case narratives should have been included to assess the level of understanding acquired at the end of the didactic lecture. Translation of this skill to proficiency stage in future and voluntary reporting of ADR at a later stage can be assured by conducting similar exercises on a regular basis and suggesting a compulsory implementation of ADR reporting exercises in clinical training and internship program.

Albeit in this project, this adeptness was achieved only by the second professional MBBS students, this can accommodate as an example for the future development of ADR module and implement it in their in clinical training and internship program. Thus, if all medical schools in India incorporate the ADR reporting adeptness in their curriculum, definitely future health-care professionals will be competent and confident in reporting the ADR.

\section{ACKNOWLEDGEMENTS}

Author extends her gratitude to the Himalayan institute of Medical sciences for smooth conduction of the project work. The author is indebted to and fortunate enough to get constant encouragement, support, and guidance from Dr. Taruna Sharma, Dr. Suman Bala along with all Teaching members of Department of Pharmacology, which helped in the successful completion of the project work. Also, author would like to extend her gratitude to her family and Mr. Aditya walia for their kind co-operation and encouragement. Thanking my colleagues for their timely support.

\section{Funding: No funding sources}

Conflict of interest: None declared

Ethical approval: The study was approved by the Institutional Ethics Committee

\section{REFERENCES}

1. Hema NG, Bhuvana KB. Pharmacovigilance: The Extent of Awareness Among the Final Year Students, Interns and Postgraduates in a Government Teaching Hospital. Journal of Clinical and Diagnostic Research. 2012;6(7).

2. International drug monitoring: The role of national centres. Report of a WHO meeting. World Health Organ Tech Rep Ser. 1972;498:1-25.

3. Hong BY, Tan TC. Epidemiology and risk factors for drug allergy. British Journal of Clinical Pharmacology. 2011;71(5):684-700.

4. World health organisation. Programme. World health organisation.

Available at: http://www.who.int/medicines/areas/quality_safety/sa fety_efficacy/pharmvigi/en/ Assessed Jan 032018.

5. Indian Pharmacopoeia Commission Pharmacovigilance Programme of India (PvPI). Available at: http://ipc.nic.in/writereaddata/linkimages/pvpi2611733527.pdf. Assessed January 032018.

6. The National Pharmacovigilance Protocol, Ministry of Health and Family Welfare, Govt of India. Available at: $\quad$ http://www.nlsenlaw.org/wpcontent/uploads/2013/08/National-

Pharmacovigilance-Protocol.pdf. Assessed January 22 2018.

7. Suke SG, Kosta P, Negi H. Role of pharmacovigilance in India: An overview. Online Journal of Public Health Informatics. 2015;7(2).

8. Meher BR, Joshua N, Asha B, Mukherji D. A questionnaire based study to assess knowledge, attitude and practice of pharmacovigilance among undergraduate medical students in a Tertiary Care Teaching Hospital of South India. Perspectives in clinical research. 2015 Oct; 6(4):217.

9. Indian Pharmacopoeia commission Pharmacovigilance Programme of India (PvPI). Available 
http://ipc.nic.in/index1.asp?EncHid=andlang=1 andlin kid=75andlid=254. Assessed January 222018.

10. Shankar PR, Subish P, Mishra P, Dubey AK. Teaching pharmacovigilance to medical students and doctors. Indian Journal of Pharmacology. 2006 Sep 1;38(5):316.

11. Tripathi RK, Jalgaonkar SV, Sarkate PV, Rege NN. Implementation of a module to promote competency in adverse drug reaction reporting in undergraduate medical students. Indian Journal of Pharmacology. 2016 Oct;48(1):S69.

12. Elkalmi RM, Ahmad Hassali MA, Al-lela QB, Jamshed SQ. The teaching of subjects related to pharmacovigilance in Malaysian pharmacy undergraduate programs. J Pharmacovigilance. 2013 Jan 28;1(2):1-5.

13. Abubakar AR, Chedi BA, Mohammed KG, Haque M. Perception of Nigerian medical students on adverse drug reaction reporting. Journal of advanced pharmaceutical technology and research. 2015 Oct;6(4):154

14. Sivadasan S, Sellappan M. A study on the awareness and attitude towards pharmacovigilance and adverse drug reaction reporting among nursing students in a private university, Malaysia. Int J Curr Pharm Res. 2015;7(1):84-9.

Cite this article as: Sharma N, Sharma T, Bala S. Effectiveness of a module to promote competency in adverse drug reaction reporting in undergraduate medical students. Int J Basic Clin Pharmacol 2018;7:723-8. 